\title{
Cenário epidemiológico das arboviroses no Piauí
}

\author{
Epidemiological situation of arboviruses in the state of Piauí \\ Situación epidemiológica de las arboviroses em Piauí
}

\begin{abstract}
Wanessa Landim Porto ${ }^{1 *}$, Talita Fonsêca Terto ${ }^{1}$, Lucas Carvalho Soares ${ }^{1}$, Ana Carolina Aguiar Cardoso $^{1}$, Vítor Monte de Castro Alencar ${ }^{1}$, Baldomero Antônio Kato da Silva ${ }^{2}$, Ana Rachel Oliveira de Andrade $^{3}$, Antônio de Pádua Rocha Nóbrega Neto ${ }^{3}$, Antonione Santos Bezerra Pinto ${ }^{3}$, Thiago de Souza Lopes Araújo ${ }^{3}$, José Lopes Pereira Junior ${ }^{3}$, Tereza Cristina de Souza Garcês ${ }^{3}$.
\end{abstract}

\section{RESUMO}

Objetivo: Identificar o perfil epidemiológico das infecções por arbovírus no estado do Piauí entre os anos de 2007 a 2017. Métodos: Trata-se de um estudo transversal de abordagem descritiva e retrospectiva, com dados secundários coletados através da base de dados do Sistema de Informação de Agravo de Notificação (SINAN). Resultados: De 2007 a 2017 foram notificados 91625 casos de arboviroses no estado do Piauí, destes 52.209 foram confirmados. No período estudado houve uma redução na incidência de Dengue vírus após a inserção do Chikungunya virus e Zika virus. Os adultos foram os mais acometidos pelas arboviroses, bem como o sexo feminino, apresentando assim elevada incidência. Conclusão Foi possível concluir que durante o período analisado o ano 2017 apresentou um maior número de casos confirmados, o sexo feminino foi o apresentou maior incidência da infecção, quanto à faixa etária os adultos foram os mais acometidos pela doença. Entre os municípios pesquisados Teresina foi o que mais notificou e confirmou casos de arboviroses no período estudado. Os resultados possibilitaram a compreensão do cenário das arboviroses no Piauí e, a identificação das áreas de risco para a ocorrência dos arbovírus, bem como a população mais vulnerável, o que contribuirá para o desenvolvimento das políticas de saúde.

Palavras-chave: Epidemiologia, Arboviroses, Piauí, Nordeste.

\begin{abstract}
Objective: To identify the epidemiological profile of arbovirus infections in the state of Piauí from 2007 to 2017. Methodology: This is a cross-sectional descriptive and retrospective study, with secondary data collected through Sistema de Informação de Agravo de Notificação (SINAN). Result: From 2007 to 2017 reported 91625 cases of arboviroses not state of Piauí, of these 52,209 were confirmed. In the studied period there was a reduction in the incidence of Dengue virus after the insertion of Chikungunya virus and Zika virus. The female sex presented a higher incidence in all the arboviruses, just as the adults were the most affected by the arboviruses. Conclusion: It was possible to conclude that during the analyzed period the year 2017 presented a greater number of confirmed cases, the female sex was the one with the highest incidence of infection, and the adults were the most affected by the disease. Among the municipalities surveyed Teresina was the one that most reported and confirmed cases of arboviruses in the studied period. The results made it possible to better understand the arboviruses scenario in Piauí, the identification of the risk areas for the occurrence of arboviruses as well as the most vulnerable population will contribute to health policies.
\end{abstract}

Key words: Epidemiology, Arboviroses, Piauí, Northeast.

\footnotetext{
${ }^{1}$ Discente do curso de Medicina da Faculdade de Ciências Humanas, Exatas e da Saúde do Piauí - FAHESP Instituto de Educação Superior do Vale do Parnaíba- IESVAP. *E-mail: wanessalandim_porto@hotmail.com 2Docente do curso de Fisioterapia da Universidade Federal do Delta do Parnaíba (UFDPar), Parnaíba - PI ${ }^{3}$ Docente do curso de Medicina da Faculdade de Ciências Humanas, Exatas e da Saúde do Piauí - FAHESP Instituto de Educação Superior do Vale do Parnaíba- IESVAP.
}

SUBMETIDO EM: 6/2019

ACEITO EM: 7/2019

PUBLICADO EM: $8 / 2019$ 


\section{RESUMEN}

Objetivo: El presente estudio tiene como objetivo trazar el perfil epidemiológico de las infecciones por arbovirus en el estado de Piauí entre los años de 2007 a 2017. Métodos: Se trata de un estudio transversal de abordaje descriptivo y retrospectivo, con datos secundarios recogidos a través de la base de datos del Sistema de Informação de Agravo de Notificação (SINAN). Resultados: De 2007 a 2017 se notificaron 91625 casos de arbovirosis en el estado de Piaú, de estos 52.209 fueron confirmados. En el período estudiado hubo una reducción en la incidencia de Dengue virus después de la inserción del Chikungunya virus y Zika virus. Los adultos fueron los más acometidos por los arbovirosis, así como el sexo femenino, presentando así elevada incidencia. Conclusión: Fue posible concluir que durante el período analizado el año 2017 presentó un mayor número de casos confirmados, el sexo femenino fue el que presentó mayor incidencia de la infección, en cuanto al grupo de edad los adultos fueron los más afectados por la enfermedad. Entre los municipios investigados Teresina fue el que más notificó y confirmó casos de arbovirosis en el período estudiado. Los resultados posibilitaron la comprensión del escenario de las arbovirosis en Piauí y, la identificación de las áreas de riesgo para la ocurrencia de los arbovirus, así como la población más vulnerable contribuirán a las políticas de salud.

Palabras clave: Epidemiología, Arbovirus, Piauí, Noreste.

\section{INTRODUÇÃO}

As arboviroses são infecções ocasionadas por vírus e transmitidas através da picada de artrópodes hematófagos, destacando-se o Aedes aegypti e Aedes albopictus, que servem não somente como vetor mas também como local de replicação viral (DONALISIO MR, et al., 2017; LOPES N, et al., 2014).

Nos últimos anos pelo menos nove arbovírus patogênicos circularam no Brasil causando infecções, sendo que os principais fazem parte da família Flaviviridae e Togaviridae. O Dengue virus (DENV), Zika virus (ZIKV) e West Nile virus (WNV) pertencem ao gênero Flavivirus, já o Chikungunya virus (CHIKV) e Mayaro virus (MAYV) fazem parte do gênero Alphavirus (FIGUEIREDO LTM, 2015; LOPES N, et al., 2014).

O Mayaro virus (MAYV) 1 endêmico em algumas regiões do país, e nos últimos anos está sendo registrado casos de MAYV em outras regiões, e devido sua semelhança aos sintomas do CHIKV poderá subnotificar essas infecções com consequentes epidemias nos estados brasileiros atingindo proporções globais, a demais, foram registrados casos no Mato Grosso e recentemente pesquisadores anunciaram por meio de sites a presença do vírus no Rio de Janeiro, (VIEIRA MACS, et al., 2015; ESPOSITO DLA e FONSECA BAL, 2017).

A emergência e reemergência das arboviroses têm ocorrido mundialmente e esse fenômeno está associado a múltiplos fatores, como a urbanização, saneamento básico precário, aumento das viagens, migração populacional, mudanças climáticas, recombinação viral e mutação, que favorecem a evolução e adaptação de estirpes virais (LOPES N, et al., 2014; VOGELS CBF, et al.,2019).

As infecções causadas por estes vírus podem gerar uma diversidade de sinais e sintomas inespecíficos (WASAY M, et al., 2015). As manifestações clínicas são semelhantes dificultando o diagnóstico clínico e variam de doença febril subclínica ou leve a formas graves, incluindo exantema ou rash maculopapular, hemorragia e alterações do sistema nervoso central (encefalite, meningite, meningoencefalite, mielite e acidente vascular cerebral) e podendo evoluir para óbito (GONZÁLEZ G, et al., 2003; LOPES N, et al., 2014).

O CHIKV chegou à América Latina em 2013, e os primeiros casos notificados no Brasil ocorreram nas regiões Norte e Nordeste (DIAS JP, et al., 2018). A infecção por esse vírus caracteriza-se por edema e artralgia (VOGELS CBF, et al., 2019). O primeiro caso confirmado de WNV ocorreu no Piauí em 2014 (VIEIRA MACS, et al.,2015), e o segundo caso também no Piauí só foi confirmado em 2019 (BRASIL,2019).

Existe uma dificuldade de diferenciá-la das demais arboviroses por apresentar semelhança de sintomatologia (MANIERO VC, et al., 2016). O primeiro caso ZIKV foi registrado no Brasil, no estado da Bahia em 2015 (CAMPOS GS, et al., 2015), disseminando-se rapidamente para outras regiões brasileiras, principalmente região nordeste. Atualmente é um problema de saúde pública devido as manifestações graves nas crianças cujas mães foram infectadas durante a gestação. O quadro clínico varia entre microcefalia, 
desproporção craniofacial, irritabilidade, espasticidades musculares, convulsões, bem como anormalidades visuais e auditivas (LIMA GP, et al., 2019).

São numerosos os casos de co-circulação do DENV, ZIKV e CHIKV. Acredita-se que a interação das arboviroses ou casos de reinfecção pelos diferentes sorotipos de DENV podem desencadear viremias mais intensas e até mesmo predispor o desenvolvimento de doenças autoimunes como a síndrome de Guillan Barré (VOGELS CBF, et al., 2019).

Dentre os estados do Nordeste, o Piauí apresenta-se com números crescentes de notificação do ano de 2007 a 2017, no entanto o ano de 2016 não acompanhou esse padrão (BRASIL, 2012; BRASIL, 2014; BRASIL, 2015; BRASIL, 2016; BRASIL, 2017). Em 2018 apresentou a maior incidência de casos prováveis de infecção por Chikungunya (2,6 casos/100 mil habitantes) e o terceiro por Dengue (7,5 casos/100 mil habitantes) destacando-se dentre os demais estados do nordeste (BRASIL,2019). A compreensão da dinâmica das arboviroses é fundamental para a tomada de decisões acerca de ações preventivas e de controle, sendo possível elaborar políticas públicas direcionadas para a população mais vulnerável. O presente estudo tem como objetivo identificar o perfil epidemiológico das infecções por arbovírus no estado do Piauí entre os anos de 2007 a 2017.

\section{MÉTODOS}

Trata-se de um estudo transversal de abordagem descritiva e retrospectiva realizado durante os anos de 2007 a 2017. A pesquisa foi realizada no estado do Piauí, localizado na parte oeste do nordeste brasileiro. Possui uma área de $252.358 \mathrm{~km}$ e população estimada de 3.219 .257 pessoas, com uma densidade geográfica de 12,40 habitantes por $\mathrm{km}^{2}$ (BRASIL, 2010).

O clima predominante é o tropical e semi-árido sendo que as precipitações pluviométricas ocorrem entre os meses de dezembro a maio na região norte do estado e entre os meses de novembro a março na região sul (IBGE, 2010). Incluiu-se no estudo todos os casos confirmados de Dengue, Zika, Chikungunya e Febre do Nilo Ocidental entre os anos entre os anos de 2007 a 2017.

Foram considerados casos confirmados por critério laboratorial utilizando o ELISA (Enzyme Linked Immunono Sorbent Assay) e o RT-PCR (Reverse Transcription Polimerase Chain Reaction) e clínicoepidemiológico analisando a presença de febre, cefaleia, dor retroorbitária, mialgia, artralgia, exantema. Para isso utilizou-se a definição do Ministério da Saúde (BRASIL,2016).

Os dados epidemiológicos foram coletados na Secretaria de Estado da Saúde do Piauí (SESAPI), através do Sistema de Informações de Agravos de Notificação (SINAN), os casos de Dengue foram obtidos das duas diferentes versões: SINAN -NET (2007 a 2014) e SINAN- OLINE (2015 a 2017).

Para a tabulação dos dados utilizou-se o software Microsoft Office Excel囚 2010(MICROSOFT, 2010). E para a configuração dos gráficos utilizou-se o programa GraphPad Prism 5.0. As variáveis coletadas para a realização do estudo foram: número de casos confirmados, distribuição dos casos quanto ao sexo, idade, município de residência.

Para a realização do estudo foram respeitadas as diretrizes e critérios éticos estabelecidos na Resolução 466/12 do Conselho Nacional de Saúde (CNS). Por se tratar de dados secundários, sem identificação dos casos não se faz necessário a aprovação do Comitê de ética em Pesquisa.

\section{RESULTADOS}

Durante o período analisado, foram notificados 78.716 casos de DENV, desses 45.180 foram confirmados. Dos quais $26.139(57,85 \%)$ foram do sexo feminino, 19.006 (42,06\%) do sexo masculino e $35(0,08 \%)$ pacientes tiveram sexo ignorado.

Ao observar a faixa etária mais acometida é possível perceber que os adultos foram os mais acometidos pela infecção, a idade média foi entre 23,2 a 43,9 anos, conforme mostra Tabela 1. 
Tabela 1 - Quantificação dos casos de dengue segundo sexo e idade.

\begin{tabular}{cccccccc}
\hline & Casos & Masculino & Feminino & Sexo ignorado & Idade min & Idade max & Idade média \\
\hline 2007 & 9040 & 3733 & 5305 & 2 & 1 mês & 97 & 23,2 \\
2008 & 1984 & 845 & 1139 & - & 1 mês & 92 & 27,2 \\
2009 & 3604 & 1495 & 2109 & - & 1 mês & 91 & 31,3 \\
2010 & 5944 & 2492 & 3452 & - & 1 mês & 97 & 30,3 \\
2011 & 9371 & 4208 & 5162 & 1 & 1 mês & 93 & 28,8 \\
2012 & 1036 & 429 & 607 & - & 4 meses & 81 & 41,9 \\
2013 & 238 & 105 & 133 & - & 5 meses & 87 & 38,7 \\
2014 & 162 & 62 & 100 & - & 27 & 44 & 43,9 \\
2015 & 6248 & 2535 & 3708 & 5 & 1 mês & 94 & 40,3 \\
2016 & 3548 & 1459 & 2077 & 12 & 1 mês & 94 & 35,2 \\
2017 & 4005 & 1643 & 2347 & 15 & 1 mês & 93 & 34,9 \\
Total & $\mathbf{4 5 . 1 8 0}$ & $\mathbf{1 9 . 0 0 6}$ & $\mathbf{2 6 . 1 3 9}$ & $\mathbf{3 5}$ & & & \\
\hline
\end{tabular}

Fonte: SESAPI, 2018.

Quanto ao diagnóstico foram utilizados dois critérios para confirmação, o clínico-epidemiológico e o laboratorial. Sendo que, 21.472 casos de DENV foram confirmados pelo critério clínico epidemiológico e 23.687 casos através do critério laboratorial. Dentre os exames laboratoriais o mais realizado foi a sorologia, sendo critério confirmatório em 13.922 dos casos, enquanto apenas 5 casos foram confirmados por PCR, segundo mostra Tabela 2.

Tabela 2 - Quantificação dos casos de dengue segundo classificação final, critérios diagnósticos e evolução.

\begin{tabular}{|c|c|c|c|c|c|c|c|c|c|}
\hline & \multicolumn{3}{|c|}{ Classificação } & \multicolumn{3}{|c|}{ Critério diagnóstico } & \multicolumn{3}{|c|}{ Evolução } \\
\hline & Dengue & $\begin{array}{l}\text { Dengue } \\
\text { SCA }\end{array}$ & $\begin{array}{l}\text { Dengue } \\
\text { grave }\end{array}$ & $\begin{array}{l}\text { Clinico/ } \\
\text { Epidemiológico }\end{array}$ & Laborat. & $\begin{array}{c}\text { Em } \\
\text { investig. }\end{array}$ & Cura & NI & Obito \\
\hline 2007 & 9031 & 2 & 7 & 3959 & 5081 & - & 9039 & 1 & - \\
\hline 2008 & 1975 & 1 & 8 & 1636 & 348 & - & 1981 & 3 & - \\
\hline 2009 & 3594 & - & 10 & 1150 & 2454 & - & 3604 & - & - \\
\hline 2010 & 5575 & 339 & 30 & 1321 & 4623 & - & 5929 & $\begin{array}{l}1 \\
4\end{array}$ & 1 \\
\hline 2011 & 9324 & 33 & 14 & 4980 & 4391 & - & 9346 & $\begin{array}{l}2 \\
5\end{array}$ & - \\
\hline 2012 & 1033 & - & 3 & 285 & 751 & - & 1034 & 1 & 1 \\
\hline 2013 & 237 & 1 & - & 202 & 36 & - & 237 & 1 & - \\
\hline 2014 & 162 & - & - & 114 & 48 & - & 160 & 2 & - \\
\hline 2015 & 6243 & 4 & 1 & 1726 & 4520 & 2 & 6222 & $\begin{array}{l}1 \\
2\end{array}$ & \\
\hline 2016 & 3547 & 1 & - & 3025 & 519 & 4 & 3383 & $\begin{array}{l}1 \\
6 \\
5\end{array}$ & - \\
\hline 2017 & 4003 & 2 & - & 3074 & 916 & 15 & 3107 & $\begin{array}{l}8 \\
9 \\
8\end{array}$ & - \\
\hline Total & & & & 21.472 & 23.687 & 21 & & & \\
\hline
\end{tabular}

Fonte: SESAPI, 2018.

No período estudado, foram notificados 11.641 casos de CHIKV, desses 6.917 foram confirmados. Dos casos confirmados $4.387(63,42 \%)$ foram do sexo feminino, e $2.511(36,31 \%)$ do sexo masculino e $19(0,27 \%)$ pacientes tiveram sexo ignorado. A idade média acometida foi entre 32,6 e 58 anos, assim a faixa etária mais prevalente é a adulta, conforme mostra a Tabela 3. 
Tabela 3 - Quantificação dos casos de Chikungunya segundo sexo, idade e sorologia.

\begin{tabular}{ccccccccc}
\hline & Casos & Mascul. & Feminin. & $\begin{array}{c}\text { Sexo } \\
\text { ignorado }\end{array}$ & $\begin{array}{c}\text { Idade } \\
\text { mínima }\end{array}$ & $\begin{array}{c}\text { Idade } \\
\text { máxima }\end{array}$ & $\begin{array}{c}\text { Idade } \\
\text { média }\end{array}$ & $\begin{array}{c}\text { Soro } \\
\text { NI }\end{array}$ \\
\hline 2015 & 3 & 1 & 2 & - & 45 & 77 & 58 & 3 \\
2016 & 1467 & 550 & 914 & 3 & 1 & 95 & 39,2 & 1467 \\
2017 & 5447 & 1960 & 3471 & 16 & 1 mês & 90 & 32,6 & 5447 \\
Total & $\mathbf{6 . 9 1 7}$ & $\mathbf{2 . 5 1 1}$ & $\mathbf{4 . 3 8 7}$ & $\mathbf{1 9}$ & & & & \\
\hline
\end{tabular}

Fonte: SESAPI, 2018.

Quanto ao critério diagnóstico do CHIKV, foram utilizadas duas variáveis, a clínico epidemiológico e a laboratorial, em que $5944(71,21 \%)$ e $2390(28,63 \%)$ dos pacientes tiveram confirmação por esses critérios respectivamente, e $13(0,16 \%)$ pacientes estavam em investigação ou o critério não foi identificado. Observamos que o PCR não foi realizado na maioria dos indivíduos acometidos por CHIKV conforma ilustra a Tabela 4.

Tabela 4 - Quantificação dos casos de Chikungunya segundo PCR, critérios diagnósticos e evolução.

\begin{tabular}{lccc|cccc|cc}
\hline & \multicolumn{3}{c}{ PCR } & \multicolumn{3}{c|}{ Critério diagnóstico } & \multicolumn{2}{c}{ Evolução } \\
\cline { 2 - 9 } & Reagente & $\begin{array}{c}\text { Não } \\
\text { realizada }\end{array}$ & NI & $\begin{array}{c}\text { Clinic/ } \\
\text { Epidemiol. }\end{array}$ & Laborat. & $\begin{array}{c}\text { Em } \\
\text { investig. }\end{array}$ & $\begin{array}{c}\text { Crit } \\
\text { NI }\end{array}$ & Cura & NI \\
\cline { 2 - 10 } 2015 & - & - & 3 & - & 3 & - & - & 3 & - \\
2016 & 2 & 1145 & 320 & 1430 & 36 & - & 1 & 1143 & 324 \\
2017 & - & 4812 & 635 & 3084 & 2351 & 12 & - & 5268 & 179 \\
Total & $\mathbf{2}$ & $\mathbf{5 . 9 5 7}$ & $\mathbf{9 5 8}$ & $\mathbf{4 . 5 1 4}$ & $\mathbf{2 . 3 9 0}$ & $\mathbf{1 2}$ & $\mathbf{1}$ & $\mathbf{6 . 4 1 4}$ & $\mathbf{5 0 3}$ \\
\hline
\end{tabular}

Fonte: SESAPI, 2018.

Entre os anos de 2007 a 2017, o número de casos de ZIKV notificados foi de 1.059, desses, 110 foram confirmados. Dentre os casos confirmados, 85 (77,27\%) se tratava do sexo feminino, enquanto apenas 25 $(22,72 \%)$ do eram do sexo masculino. Quanto à idade os pacientes apresentaram média entre 29,7 a 39 anos. O diagnóstico clinico-epidemiológico foi realizado em 79 casos e o laboratorial em 31 casos, conforme mostra Tabela 5.

Tabela 5 - Quantificação dos casos de Zika segundo sexo, idade, critérios diagnósticos.

\begin{tabular}{|c|c|c|c|c|c|c|c|c|}
\hline & \multirow[t]{2}{*}{ Casos } & \multirow[t]{2}{*}{ Masc. } & \multirow[t]{2}{*}{ Fem. } & \multirow[t]{2}{*}{$\begin{array}{l}\text { Idade } \\
\text { mínima }\end{array}$} & \multirow[t]{2}{*}{$\begin{array}{c}\text { Idade } \\
\text { máxima }\end{array}$} & \multirow[t]{2}{*}{$\begin{array}{l}\text { Idade } \\
\text { média }\end{array}$} & \multicolumn{2}{|c|}{ Critérios diagnósticos } \\
\hline & & & & & & & $\begin{array}{c}\text { Clínica/ } \\
\text { Epidemiol. }\end{array}$ & Laborat. \\
\hline 2015 & 6 & 1 & 5 & 11 & 56 & 39 & 1 & 5 \\
\hline 2016 & 63 & 18 & 45 & 2 meses & 76 & 29,7 & 57 & 6 \\
\hline 2017 & 41 & 6 & 35 & 5 & 71 & 32,5 & 21 & 20 \\
\hline Total & 110 & 25 & 85 & & & & 79 & 31 \\
\hline
\end{tabular}

Fonte: SESAPI, 2018.

Apenas um caso de WNV foi confirmado, trata-se uma criança do sexo feminino e com idade de 12 anos, o critério de diagnóstico não foi informado.

Quanto à incidência dos arbovírus, foi observada que após a inserção do CHIKV no ano de 2015 a incidência DENV caiu nos anos subsequentes, já a incidência de ZIKV manteve-se praticamente constante, apresentando apenas um leve aumento no ano de 2016, segundo mostra Figura 1.

Os casos confirmados de DENV nos municípios do Piauí no período analisado, apresentam-se da seguinte maneira, Teresina teve 3.155 casos, Floriano 1.671 casos, Picos 448 , Piripiri 437 e os demais municípios 10.794, já os casos confirmados de CHIKV foram 4.633 em Teresina, Parnaíba 939, Floriano 262, Picos 58, Piripiri 46 e os outros municípios 980 casos. Os casos de ZIKV tiveram uma menor expressão sendo 
confirmados 40 casos em Teresina, 29 em Piripiri, Picos 2, nenhum caso foi registrado em Floriano e nos demais municípios tiveram 19 casos confirmados. Durante o período analisado foi confirmado apenas um caso de WNV no estado.

Figura 1 - Incidência anual dos casos de dengue, Chikungunya e Zika nos anos de 2015, 2016 e 2017.

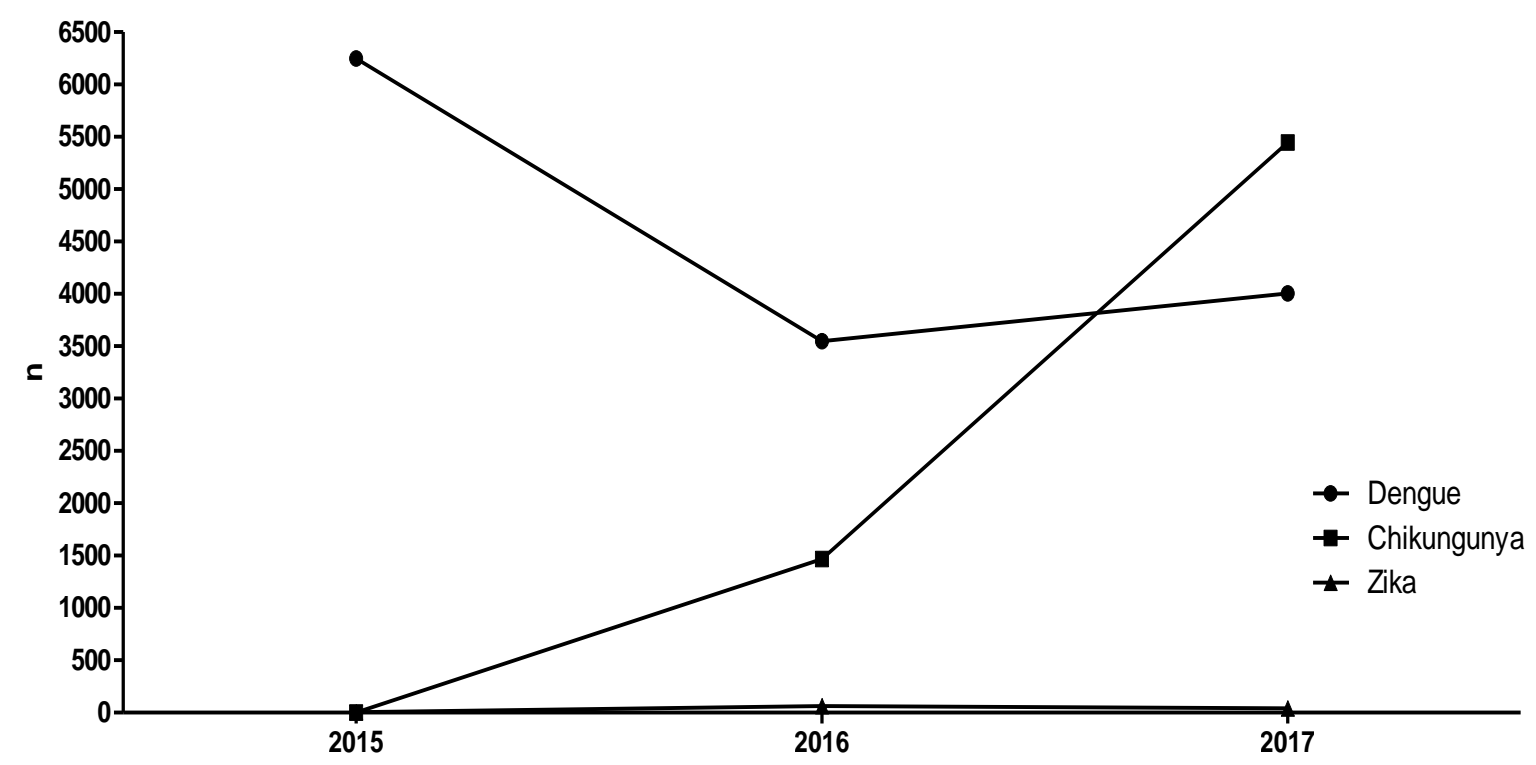

Fonte: SESAPI, 2018.

\section{DISCUSSÃO}

A análise descritiva do cenário de transmissão do DENV, CHIKV, ZIKV e WNV no estado do Piauí no período analisado revelou que o ano de 2007 destacou-se com a maior notificação de casos de dengue, entretanto 0 ano com maior número de casos confirmados foi 2011.

Em 2013 e 2014 foram confirmados 238 e 162 casos de dengue respectivamente, um número significantemente abaixo dos demais anos estudados, dados estes que estão aquém ao esperado, visto que 0 estado não passou por nenhuma mudança climática que poderia influenciar no ciclo do vetor dos arbovírus, sugerindo então uma possível subnotificação dessas infecções, podendo assim, dificultar o entendimento da real distribuição das arboviroses, essa variável ocorreu também nos estudos de Bohm AW et al. (2016), e Costa SSB et al. (2018). Entretanto uma outra explicação para essa discrepância é a existência dos picos epidêmicos, que variam de um ano para o outro, devido a interação da tríade vetor, hospedeiro (homem) e vírus (TEIXEIRA MG, et al., 1999).

De acordo com Campos GS et al. (2015), o primeiro caso de ZIKV foi catalogado no Brasil no estado da Bahia em 2015, disseminando-se rapidamente para outras regiões brasileiras, entre elas o Piauí. Segundo Donalisio MR et al. (2017) e Azevedo RSS et al. (2015) o mesmo ocorreu com CHIKV, que foi introduzido no Brasil em 2014 no Amapá e alcançou outros estados da federação, chegando ao Piauí em 2015. Nos anos subsequentes houve aumento significativo dos casos confirmados de ambas as arboviroses.

Diferentemente dos arbovírus supracitados, que foram introduzidos no Brasil por outros estados, que não o Piaú́, o primeiro caso de Febre do Nilo Ocidental notificado e confirmado pelo SINAN ocorreu no estado do Piauí no ano de 2015, embora o artigo de Vieira MACS et al. (2015) relate um caso confirmado laboratorialmente no ano de 2014.

Já em 2019 o Ministério da Saúde notificou a ocorrência de mais um caso de infecção pelo WNV no Piauí, contudo não existem relatos na literatura e tão pouco notificação no SINAM, havendo apenas em sites de notícias. 
Vários fatores contribuem para a circulação dos arbovírus no estado do Piauí, e entre os principais estão a geografia e o clima tropical da região, que possibilitam a adaptação do vírus, enquanto as altas temperaturas e o índice pluviométrico contribuem na dinâmica dos vetores (JONES KE, et al., 2008). O estado imunológico dos hospedeiros, e as condições socioeconômicas também favorecem o ciclo de vida dos arbovírus, conforme diz Donalisio MR et al. (2017) e Jones KE et al. (2008).

A co-circulação dos arbovírus tem tornado difícil o diagnóstico das infecções, uma vez que os perfis clínicos iniciais são bastante semelhantes e os exames laboratoriais nem sempre estão disponíveis, quando a sorologia está disponível pode ocorrer reatividade cruzada de soros imunes entre membros da mesma família (MISHRA $\mathrm{N}$,et al., 2018). Quando há suspeita for infecção por ZIKV em áreas onde há a notificação de infecções por outros flavivírus o exame pode apresentar um falso positivo devido às reações cruzadas, onde um anticorpo gerado por uma infecção prévia reage na infecção por ZIKV (SBI, 2016).

Colombo TE et al. (2017), enfatiza a importância das análises clínicas detalhadas nos primeiros três dias de sintomatologia e sugerem que o seguimento seja realizado com diagnóstico laboratorial e acompanhamento da progressão clínica do paciente.

Estudos como os realizados por Koishi ACK et al. (2018) demonstram, a importância do diagnóstico laboratorial realizado no período correto e com a técnica correta para que seja realizado um diagnóstico preciso e sem falsos positivos. Os achados encontrados no presente estudo, vão em consonância com a recomendação dos autores, já que a maioria dos diagnósticos foram feitos por análise laboratorial. Entre os métodos diagnósticos utilizados estão ELISA, e a RT-PCR (MANIERO VC et al., 2016).

O ELISA rastreia a imunoglobulina $M(\operatorname{lgM})$ e a imunoglobulina $G(\lg G)$ presente no sangue; esse teste na dengue identifica IgM específico desse arbovírus, sendo que nas infecções primarias ocorre aumento significativo dessa imunoglobulina detectando-a entre o quarto e o quinto dia após a febre (POOJA C, et al., 2014). Na zika o exame é inespecífico pois pode apresentar um falso positivo devido às reações cruzadas. $\mathrm{Na}$ infecção por CHIKV, a IgM produzida pela presença do patógeno é detectada no período correspondente (três a cinco semanas) após a sintomatologia, porém há pacientes que só irão produzir tal imunoglobulina entre a $6^{\underline{a}}$ e a $12^{a}$ semana (CASTRO APCR, et al., 2016). No WNV esse teste pode ser feito após o início dos sintomas (PAUVOLID-CORREAA A e VARELLA RB, 2008).

A RT-PCR detecta o vírus infectante e possibilita diferenciar qual arbovírus está presente no sangue do paciente, sendo considerada um método diagnóstico conclusivo. Nas arboviroses em geral esse teste diagnóstico é realizado nas primeiras semanas, utilizando o sangue ou a urina. Um adendo para a detecção de WNV, limitada devido a sua viremia ser baixa e transitória. (MANIERO VC, et al., 2016; PAUVOLID-CORRÊA A e VARELLA RB, 2008). Ao se observar a incidência das arboviroses segundo faixas etárias, verifica-se que a maior incidência ocorreu entre adultos, corroborando com resultados encontrados em outros estudos realizados nacionalmente assim como resultados de estudos restritos a região Nordeste. Bohm AW et al. (2016) realizou um levantamento epidemiológico da incidência de dengue no Brasil que também fala a favor da maior incidência em adultos.

De acordo com um estudo realizado recentemente na região metropolitana de Recife, foi possível constatar que 55\% dos pacientes que apresentaram SGB após infecção ZIKV apresentava idade média de 44 anos (NOBREGA MEB, et.al, 2018), em outra pesquisa realizada por Malta JMAS et al. (2017) no estado da Bahia a idade média dos pacientes com SGB após infecção pelo zika virus era inferior a 50 anos, uma outra pesquisa realizada em Fortaleza no período de 2001 a 2012 mostrou que a maioria das notificações de casos de dengue ocorreram em adultos na faixa etária de 20 a 49 anos (OLIVEIRA RMAB, et al.,2018).

Em relação ao sexo, observou-se o predomínio das arboviroses no sexo feminino, sendo esse responsável por $58,64 \%$ dos casos em detrimento ao masculino com $41,26 \%$, isso se deve ao regime predominantemente doméstico do vetor, além do fato de que as mulheres usufruem mais do sistema de saúde em comparação ao sexo oposto e esse foi o padrão descrito em alguns estudos, a exemplo o de Oliveira RMAB et al. (2018) quando eles analisaram o perfil do CHIKV, assim como na pesquisa de Monteiro ESC et al. (2009) ao estudarem o DENV.

REAS/EJCH | Vol.11(14) | e1054 | DOI: https://doi.org/10.25248/reas.e1054.2019 Página 7 de 9 
Dentre os municípios é possível destacar os cinco maiores do estado do Piauí segundo a estimativa do IBGE (Instituto Brasileiro de Geografia e Estatística) para o ano de 2018, a saber: Teresina (861.442 pessoas), Parnaíba (152.653 pessoas), Picos (78.002 pessoas), Piripiri (63.694 pessoas), Floriano (59.840 pessoas). O município que apresentou maior número de notificações foi Teresina, devido sua dimensão territorial e densidade populacional, tornando um maior número de pessoas susceptível ao vetor, isso que Scandar SAS et al. (2010) já havia demonstrado esse padrão em São José do Rio Preto. Fatores como clima e densidade populacional estão bem estabelecidos na literatura como associados à incidência das arboviroses, entretanto é possível que fatores individuais tenha pouca influência na incidência das arboviroses (MENDONÇA FA, et al., 2009).

No estudo foram encontradas particularidades referentes à incidência das arboviroses nos municípios do Piauí, como: Oeiras, localizada a aproximadamente $282 \mathrm{~km}$ da capital do estado, tendo $20 \%$ de casos confirmados de dengue em 2007 e $29 \%$ dos casos de zika em 2017, estando respectivamente no primeiro e segundo lugar no estado com os maiores números de casos.

Estudos realizados em alguns estados do Nordeste mostram a circulação dos arbovírus nessa região, por exemplo, Oliveira RMAB et al. (2018) catalogaram as epidemias de dengue entre 2001 e 2012 em Fortaleza CE, que ocorreram nos seguintes anos: 2001, 2006, 2008 e 2011, a mutabilidade dos períodos endêmicos é multifatorial, em que podemos destacar a dinâmica do vetor, os diferentes sorotipos virais e a susceptibilidade da população. Costa SSB et al. (2018) documentaram a presença das infecções por dengue, zika e chikungunya no maranhão entre 2015 e 2016. No Rio Grande do Norte o boletim epidemiológico comprova a circulação do chikungunya virus desde 2014, posteriormente confirmando casos em quase todo o estado; a dengue teve um exponencial número de notificações em 2016, já a zika obteve muitas notificações em 2015 e 2016, o que não ocorreu em 2017 e 2018 no mesmo período (BRASIL, 2018).

\section{CONCLUSÃO}

O Piauí apresenta variáveis favoráveis para a dinâmica vetorial e adaptação dos arbovírus, assim tem sido cada vez mais frequentes os casos de cocirculação, fato esse que tem comprometido o diagnóstico. Apesar da dificuldade em realizá-lo, foi possível traçar o cenário das arboviroses no Estado, evidenciando a população que se encontra em maior risco, dessa maneira as ações em políticas de saúde poderão ser direcionadas a essa população vulnerável.

\section{REFERÊNCIAS}

1. AZEVEDO RSS, OLIVEIRA CS, VASCONCELOS PFC. Chikungunya risk for Brazil. Rev. Saúde Pública, 2015.

2. BOHM AW, COSTA CS, NEVES RG, et al. Tendência da incidência de dengue no Brasil, 2002-2012 Epidemiol. Serv. Saude, Brasília, 2016.

3. BRASIL. Secretaria de Vigilância em Saúde. Boletim Epidemiológico. vol. 45. ㄲo 31. 2014.

4. BRASIL. Secretaria de Vigilância em Saúde. Boletim Epidemiológico. vol. 46. ㄲo 44. 2015.

5. BRASIL. Secretaria de Vigilância em Saúde. Boletim Epidemiológico. vol. 47. oㅡ 38. 2016.

6. BRASIL. Secretaria de Vigilância em Saúde. Boletim Epidemiológico. vol. 48. ㄲo 45. 2017.

7. BRASIL. IBGE. Censo Demográfico, 2010.

8. BRASIL. Ministério da saúde. Secretaria de vigilância à saúde. Monitoramento dos casos de dengue, febre de chikungunya e febre pelo vírus Zika até a Semana Epidemiológica 6 de 2018. Boletim Epidemiológico, Brasil, 2018.

9. BRASIL. Secretaria de Vigilância em Saúde Boletim Epidemiológico, 2019.

10. CAMPOS GS, BANDEIRA AC, SARDI SI. Zika virus outbreak, Bahia, Brazil. Emerg Infect Dis 2015.

11. CASTRO APCR, LIMA RA, NASCIMENTO JS. Chikungunya: visão do clínico da dor. Revista Dor, 2016.

12. COLOMBO TE, ESTOFOLETE CF; REIS AFN, et al. Clinical, laboratory and virological data from suspected ZIKV patients in an endemic arbovirus area. J Clin Virol. 2017.

13. COSTA SSB, BRANCO MRFC, JUNIOR, JA, et al. Spatial analysis of probable cases of dengue fever, chikungunya fever and zika virus infections in Maranhao State, Brazil. Rev. Inst. Med. trop., 2018.

14. DIAS JP, COSTA MCN, CAMPOS GS, et al. Seroprevalence of Chikungunya Virus in 2 Urban Areas of Brazil 1 Year after Emergence. Emerging Infectious Diseases, 2018. 
15. DONALISIO MR, FREITAS ARR, ZUBEN APBV. Arboviruses emerging in Brazil: challenges for clinic and implications for public health. Rev. Saúde Pública, 2017.

16. ESPOSITO DLA, FONSECA BAL. Will Mayaro virus be responsible for the next outbreak of an arthropod-borne virus in Brazil?, 2017.

17. FIGUEIREDO LTM. The recent arbovirus disease epidemic in Brazil. Revista Revista Sociedade Brasileira de. Medicina Tropical, 2015.

18. GONZALES G, BENAVIDES A, FERNÁNDEZ J. Manifestaciones Neurológicas del Dengue. Revista Chilena de NeuroPsiquiatria, 2003.

19. JONES KE, PATEL NG, LEVY MA, et al. Global trends in emerging infectious diseases. Nature, 2008.

20. KOISHI ACK, SUZUKAWA AA, ZANLUCA C, et al. Development and evaluation of a novel highthroughput imagebased fluorescent neutralization test for detection of Zika virus infection. PLOS Neglected Tropical Diseases, 2018.

21. LIMA GP, ROZENBAUM D, PIMENTEL C, et al. Factors associated with the development of Congenital Zika Syndrome: a case-control study. BMC Infectious Diseases, 2019.

22. LOPES N, NOZAWA C, LINHARES.REC. Características gerais e epidemiologia dos arbovírus emergentes no Brasil. Revista Pan-Amaz Saude, 2014.

23. MALTA JMAS, VARGAS A, LEITE PL, et al. Síndrome de Guillain-Barré e outras manifestações neurológicas possivelmente relacionadas à infecção pelo vírus Zika em municípios da Bahia, 2015. Epidemiol. Serv. Saude, Brasília, 2017.

24. MANIERO VC, SANTOS MO, RIBEIRO RL, et al. Dengue, chikungunya e zika vírus no brasil: situação epidemiológica, aspectos clínicos e medidas preventivas. Almanaque multidisciplinar de pesquisa, 2016.

25. MENDONÇA FA, SOUZA AV, DUTRA DA. Saúde pública, urbanização e dengue no Brasil. Soc Nat., 2009.

26. MISHRA N, CACIULA A, PRICE A, et al. Diagnosis of Zika Virus Infection by Peptide Array and Enzyme-Linked Immunosorbent Assay. mBio, 2018.

27. MONTEIRO ESC, COELHO ME, CUNHA IS, et al. Aspectos epidemiológicos e vetoriais da dengue na cidade de Teresina, Piauí - Brasil, 2002 a 2006. Epidemiol. Serv. Saúde, 2009.

28. NÓBREGA MEB, ARAÚJO ELL, WADA MY, et al. Surto de síndrome de Guillain-Barré possivelmente relacionado à infecção prévia pelo vírus Zika, Região Metropolitana do Recife, Pernambuco, Brasil, 2015. Epidemiol. Serv. Saude, Brasília, 2018.

29. OLIVEIRA RMAB, ARAUJO FMC, CAVALCANTI LPG. Aspectos entomológicos e epidemiológicos das epidemias de dengue em Fortaleza, Ceará, 2001-2012*. Epidemiol. Serv. Saude, Brasília, 2018.

30. PAUVOLID-CORRÊA A; VARELLA R.B. Aspectos epidemiológicos da febre do Nilo Ocidental. Rev Bras Epidemiol, 2008.

31. POOJA C, AMRITA Y, VINEY C. Clinical implications and treatment of dengue. Asian Pacific Journal of Tropical Medicine, 2014.

32. RIO GRANDE DO NORTE. Secretaria de Estado da Saúde Pública. Coordenadoria de Promoção à Saúde. Sub coordenadoria de Vigilância Epidemiológica. Boletim Epidemiológico, 2018.

33. SCANDAR SAS, VIEIRA P, CARDOSO JUNIOR, RP, et al. Dengue em São José do Rio Preto, Estado de São Paulo, Brasil, 1990 a 2005: fatores entomológicos, ambientais e socioeconômicos. Bol Epidemiol Paulista, 2010.

34. SOCIEDADE BRASILEIRA DE INFECTOLOGIA -SBI. Guia de manejo de infecção pelo vírus zika. Brasil, 2016.

35. TEIXEIRA MG, BARRETO ML, GUERRA Z. Epidemiologia e medidas de prevenção do Dengue. Inf. Epidemiol, 1999.

36. VIEIRA MACS, ROMANO APM, BORBA AS, et al. Case Report: West Nile Virus Encephalitis: The First Human Case Recorded in Brazil. Am. J. Trop. Med. Hyg, 2015.

37. VOGELS CBF, RUCEKERT C, CAVANY SM, et al. Arbovirus coinfection and co-transmission: A neglected public health concern? PLOS Biology, 2019.

38. WASAY M, KHATRI IA, ABD AF. Arbovirus infections of the nervous system: current trends and future threats. American Academy of Neurology, 2015. 